\title{
DETERMINANTES AMBIENTALES Y SOCIALES PARA LA REEMERGENCIA DE LA LEPTOSPIROSIS EN LA REGIÓN AMAZÓNICA DEL PERÚ, 2012
}

\section{ENVIRONMENTAL AND SOCIAL DETERMINANT FACTORS FOR THE REEMERGENCE OF LEPTOSPIROSIS IN THE AMAZON REGION OF PERU, 2012}

\author{
Luis F. Donaires ${ }^{1, a}$, Manuel J. Céspedes ${ }^{1, b}$, Moisés G. Sihuincha ${ }^{2, a}$, Paúl E. Pachas ${ }^{1, c}$
}

\begin{abstract}
La leptospirosis es una enfermedad zoonótica de importancia global causada por especies patógenas de Leptospira sp. Se presenta en áreas rurales y urbanas, particularmente en regiones de la Amazonía como Loreto o Madre de Dios, donde constituye la zoonosis bacteriana más prevalente. Su presentación clínica va desde una enfermedad febril indiferenciada a una enfermedad grave con compromiso multisistémico de elevada letalidad ${ }^{(1)}$.
\end{abstract}

La ecología de la leptospirosis involucra una compleja interacción entre los seres humanos, los reservorios animales, el agente etiológico y el medioambiente donde coexisten; por lo que se presentan diferentes patrones epidemiológicos en función del entorno ecológico (2).

En zonas rurales, la transmisión se encuentra asociada con actividades agrícolas y ganaderas, lo cual difiere de lo encontrado en estudios conducidos en la Amazonía

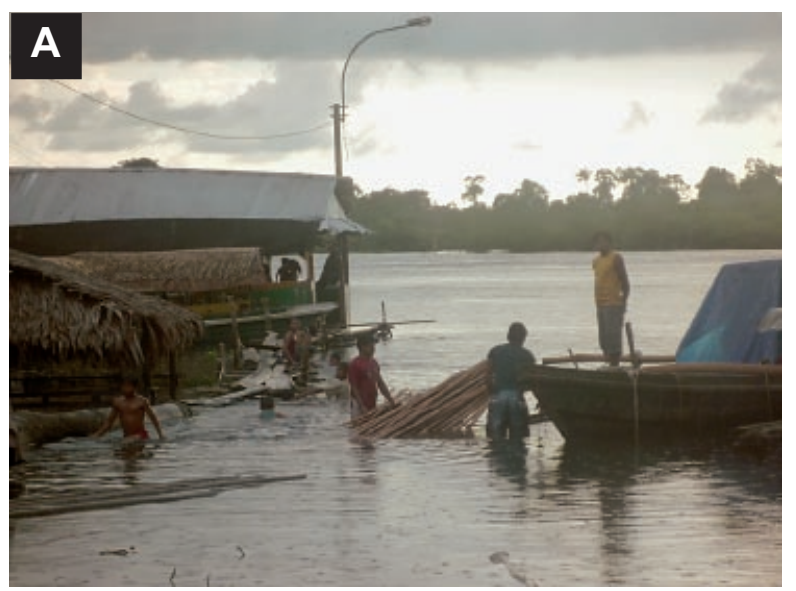

peruana, donde la infección está asociada con tener contacto directo con agua de los ríos, saneamiento deficiente, y no usar calzado (3) (Figura 1). En las zonas urbanas la infección se asocia con el hacinamiento; vivir en áreas inundables o cercanas a los ríos; saneamiento inadecuado, y pobreza ${ }^{(4)}$; presentes en zonas marginales de las ciudades de la Amazonía peruana.

Además, existen múltiples determinantes ambientales que han sido implicados en la dinámica de transmisión de la leptospirosis, los cuales incluyen al cambio climático, fenómenos meteorológicos extremos, utilización de la tierra, comercio internacional, reservorios animales y prácticas agrícolas, y otras actividades antropogénicas. En las últimas décadas, factores importantes como las lluvias, inundaciones, urbanización de nuevas áreas, y actividades recreacionales, vienen incrementando el riesgo de la reemergencia de la leptospirosis.

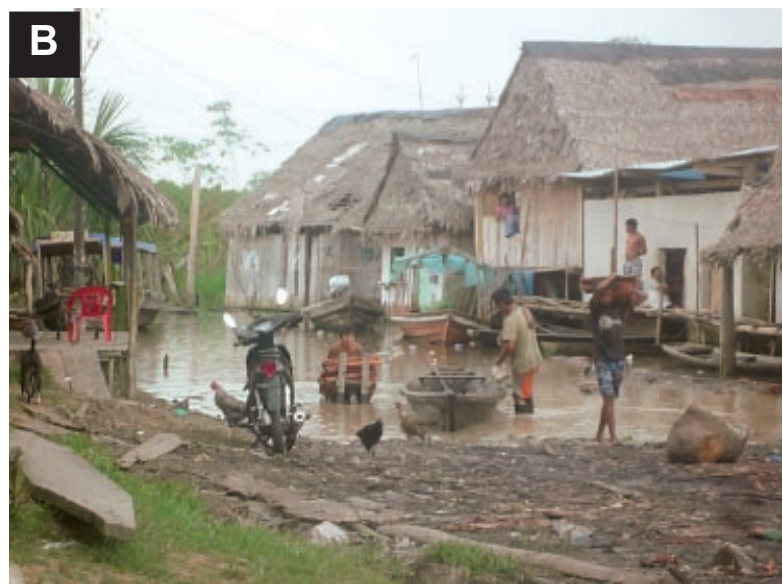

Figura 1. Actividades desarrolladas en áreas rurales y periurbanas de la ciudad de lquitos.

A) Descarga de madera transportada en botes rústicos (peque-peque); B) Casas flotantes a orillas de los ríos.

\footnotetext{
Centro Nacional de Salud Pública, Instituto Nacional de Salud. Lima, Perú.

Hospital Apoyo Iquitos César Garayar García, Dirección Regional de Loreto. Iquitos, Perú.

Médico infectólogo; ${ }^{\mathrm{b}}$ biólogo magíster en Salud Pública; ${ }^{\mathrm{c}}$ médico epidemiólogo
} 
En todo el mundo se ha informado de numerosos brotes de leptospirosis después de inundaciones. Estos brotes estuvieron relacionados con la interrupción de los servicios públicos de salud, deterioro de las redes de saneamiento, desplazamiento de poblaciones, daño de viviendas y aumento de la exposición ambiental a los patógenos ${ }^{(2)}$. Esta situación se repite en Loreto, donde los casos de leptospirosis informados por la Dirección Regional de Salud procedieron de zonas inundadas debido a desbordes de los ríos Itaya, Nanay y el Amazonas; asociados al crecimiento poblacional desmedido y la urbanización desorganizada de los barrios marginales a las riberas de grandes ríos (Figura 2).
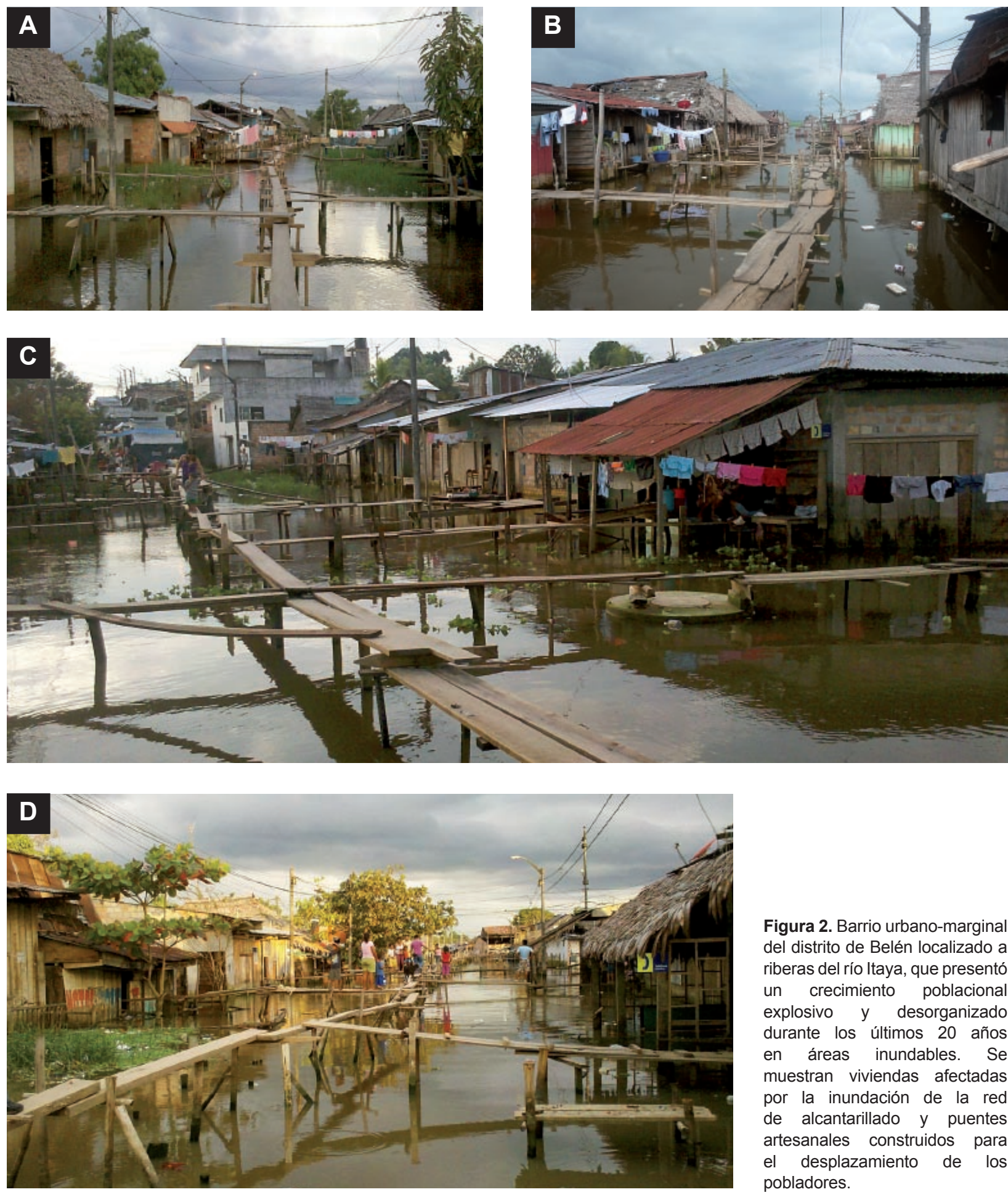

Figura 2. Barrio urbano-marginal del distrito de Belén localizado a riberas del río Itaya, que presentó un crecimiento poblacional explosivo y desorganizado durante los últimos 20 años en áreas inundables. Se muestran viviendas afectadas por la inundación de la red de alcantarillado y puentes artesanales construidos para el desplazamiento de los pobladores. 

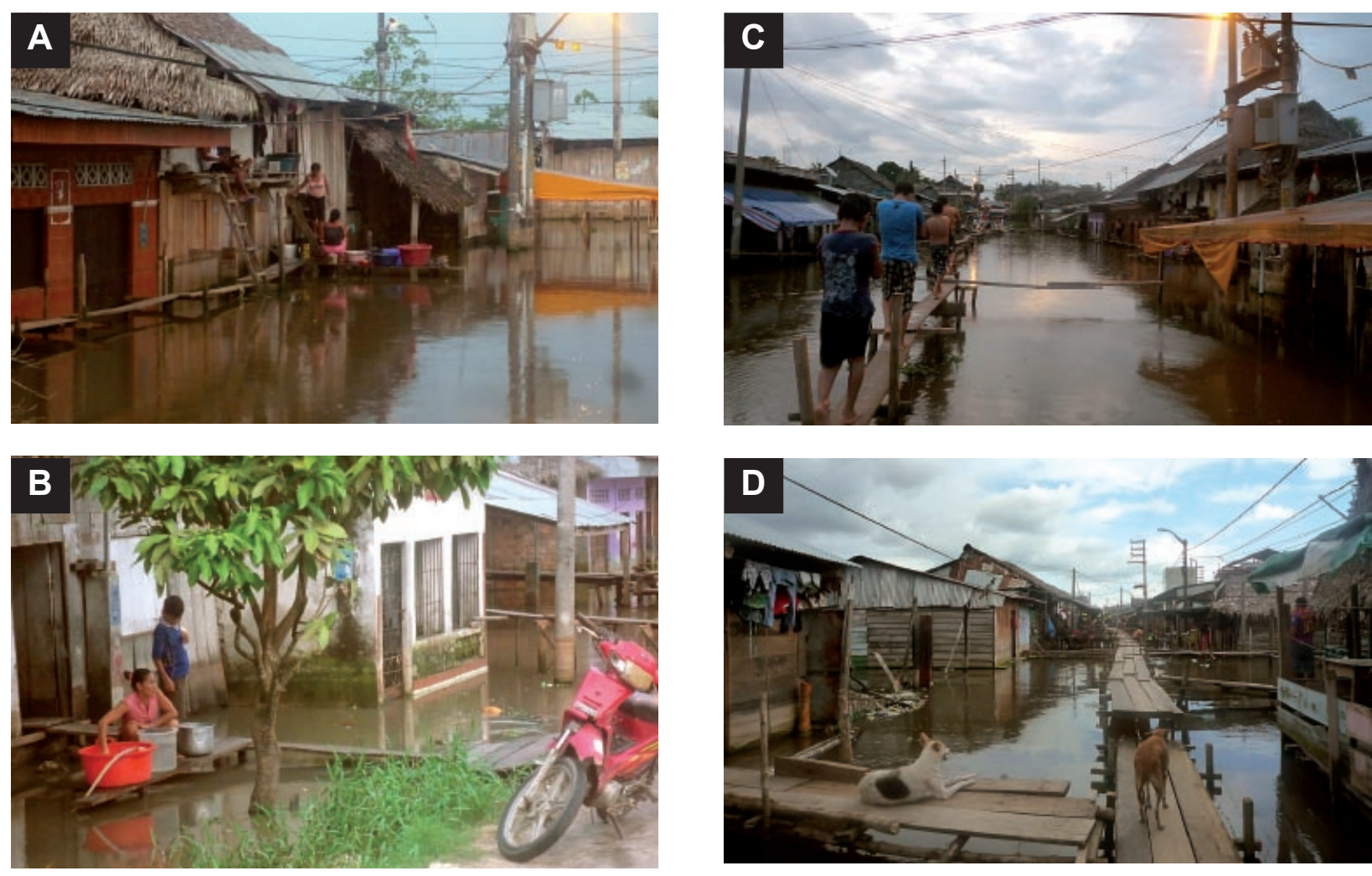

Figura 3. La pobreza y el crecimiento de barrios urbano-marginales de forma desorganizada en áreas potencialmente inundables favorecerían el incremento de leptospirosis en Loreto, Perú.

A) Los pobladores realizan actividades domésticas con el agua estancada de la inundación. B) Ama de casa coleccionando agua procedente del sistema de agua potable sumergido. C) Deambulación sin calzado. D) incremento del contacto con canes.
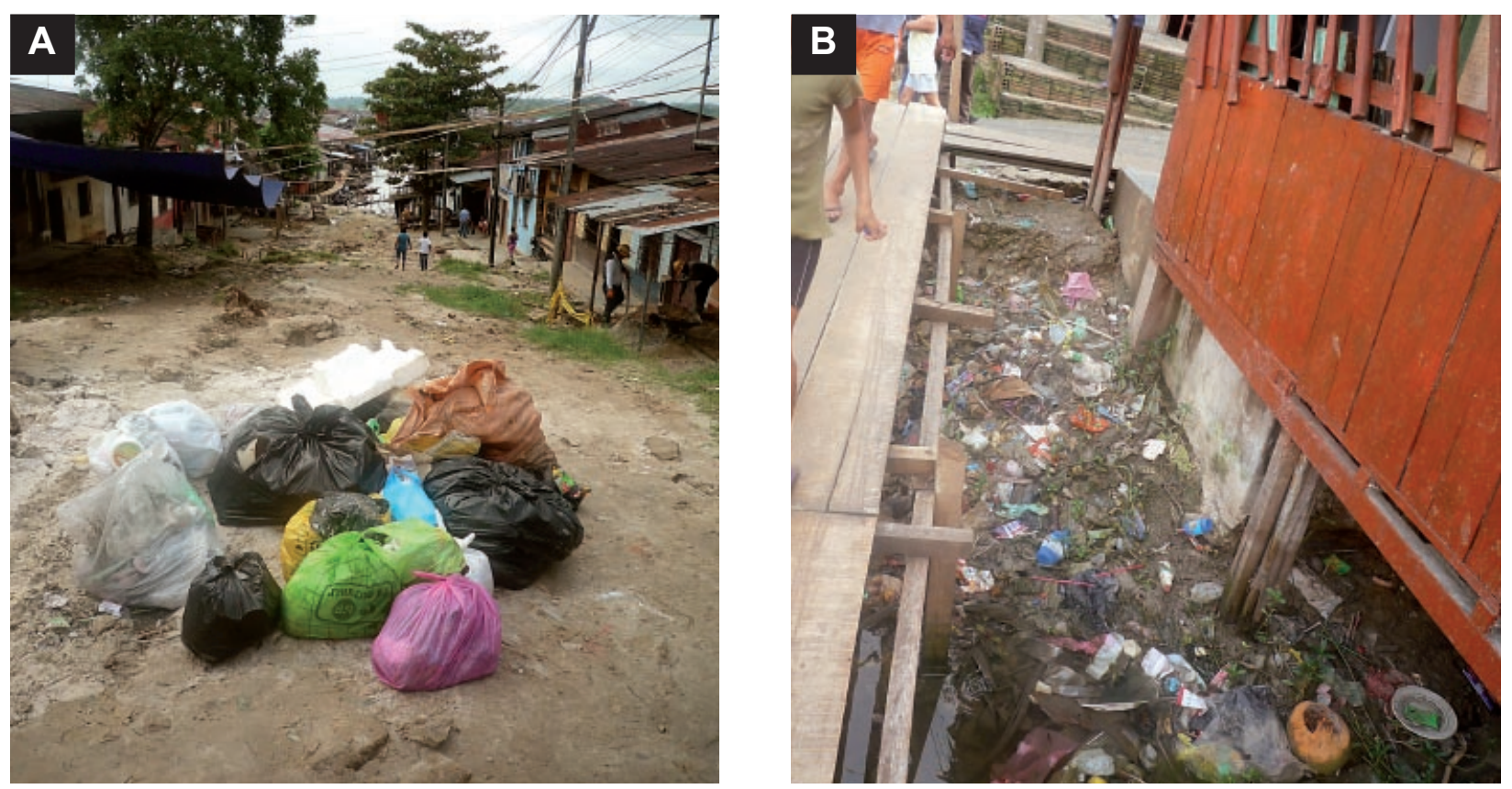

Figura 4. La inundaciones favorecen la inadecuada disposición de residuos sólidos y el colapso de las redes de alcantarillado, que contribuyen a la aparición de roedores.

A) Residuos sólidos dejados en las calles. B) Acúmulo de desperdicios en las aguas estancadas aledañas a las viviendas de las áreas inundadas. 
Así mismo, encontramos un pobre sistema de saneamiento y recolección de basura, que produce colección de basura en las calles de los barrios marginales, que junto a las precipitaciones e inundaciones influyen en el incremento de la población animal, sean roedores, aves carroñeras o perros (Figura 3 y 4 ).

\section{CARGA DE LA ENFERMEDAD Y SERVICIOS DE SALUD}

La leptospirosis es una enfermedad que a menudo pasa inadvertida, es frecuente encontrar diagnósticos erróneos debido a su presentación inespecífica que puede imitar muchas enfermedades infecciosas frecuentes en la región Amazónica, que conlleva a retrasos importantes del tratamiento y aplicación de intervenciones sanitarias específicas, crucial para minimizar la morbilidad y la mortalidad.
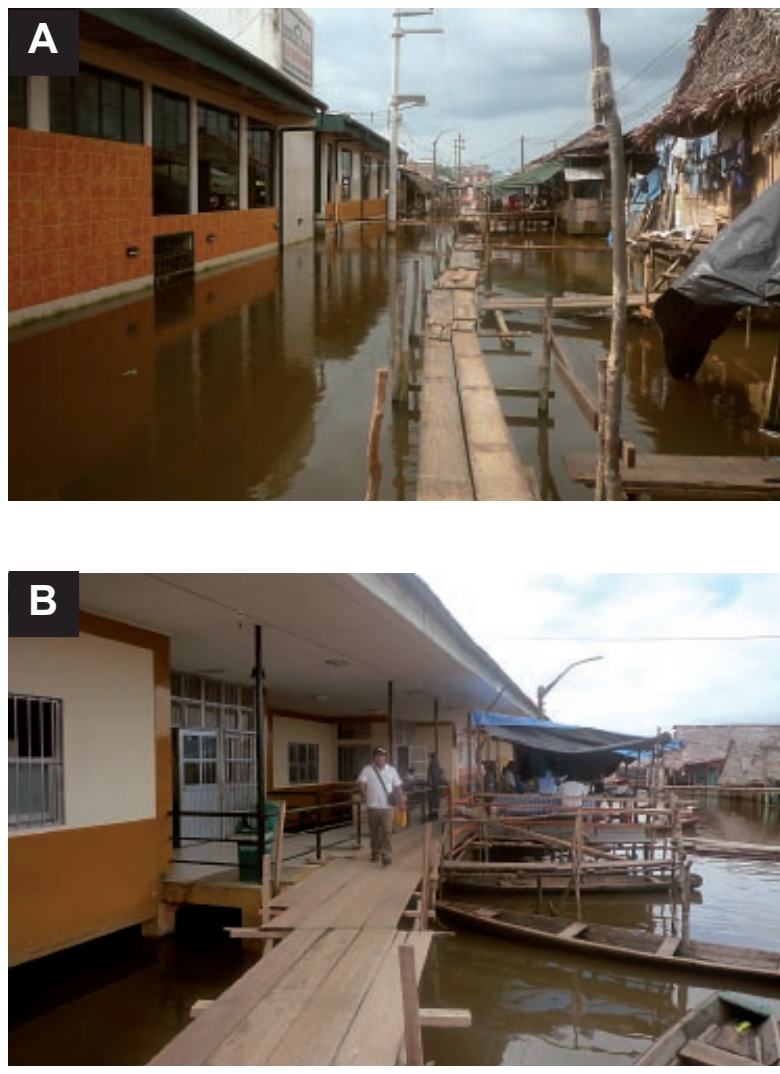

Atención primaria. Dentro de las intervenciones de control, se encuentran el reconocimiento temprano de los casos de leptospirosis por lo que se debe sospechar de la enfermedad en todo los febriles que se presenten luego de la inundación; sin embargo, los estragos del desastre hace que también los establecimientos de salud sean afectados, permitiendo la movilización de la población y los servicios de salud (Figura 5).

Atención especializada. Ante los brotes de leptospirosis es frecuente obeservar la aparición de formas graves de la enfermedad, que deben ser manejados en establecimientos especializados (en Perú, de tercer nivel). Loreto cuenta con tres hospitales que atienden la demanda de la región, a pesar de contar con unidades de cuidados críticos y especialistas de enfermedades infecciosas; aún carecen de unidades especializadas completamente implementadas para el manejo de la demanda de casos graves (Figura 6).

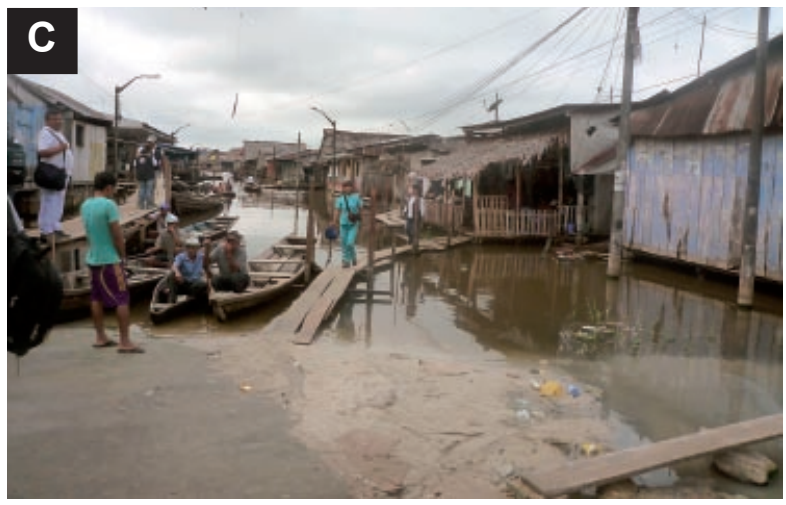

Figura 5. La inundación de localidades periurbanas con crecimiento explosivo y desordenado, condicionan factores de riesgo para la inadecuada atención de los servicios de salud primarios.

A) Centros de salud completa o B) parcialmente inundados, y C) personal de salud en actividades preventivo-promocionales en las localidades inundadas. 
Desafíos del diagnóstico de la leptospirosis en la región Amazónica. El Instituto Nacional de Salud ha implementado en el Centro de Investigación de Enfermedades Tropicales "Hugo Pesce - Maxime Kuczynski" de la ciudad de lquitos, el diagnóstico laboratorial de la fase aguda de la leptospirosis mediante los métodos de ELISA IgM para la detección de anticuerpos anti-Leptospira; cultivo de sangre; líquido cefalorraquídeo u orina en medio EMJH; pruebas de diagnóstico de biología molecular altamente sensibles y específicas como el PCR en tiempo real (Figura 7). Así mismo, los laboratorios de biomedicina del Instituto Nacional de Salud, continúan realizando las pruebas serológicas confirmatorias de la leptospirosis mediante la aglutinación microscópica con 29 serovares, el
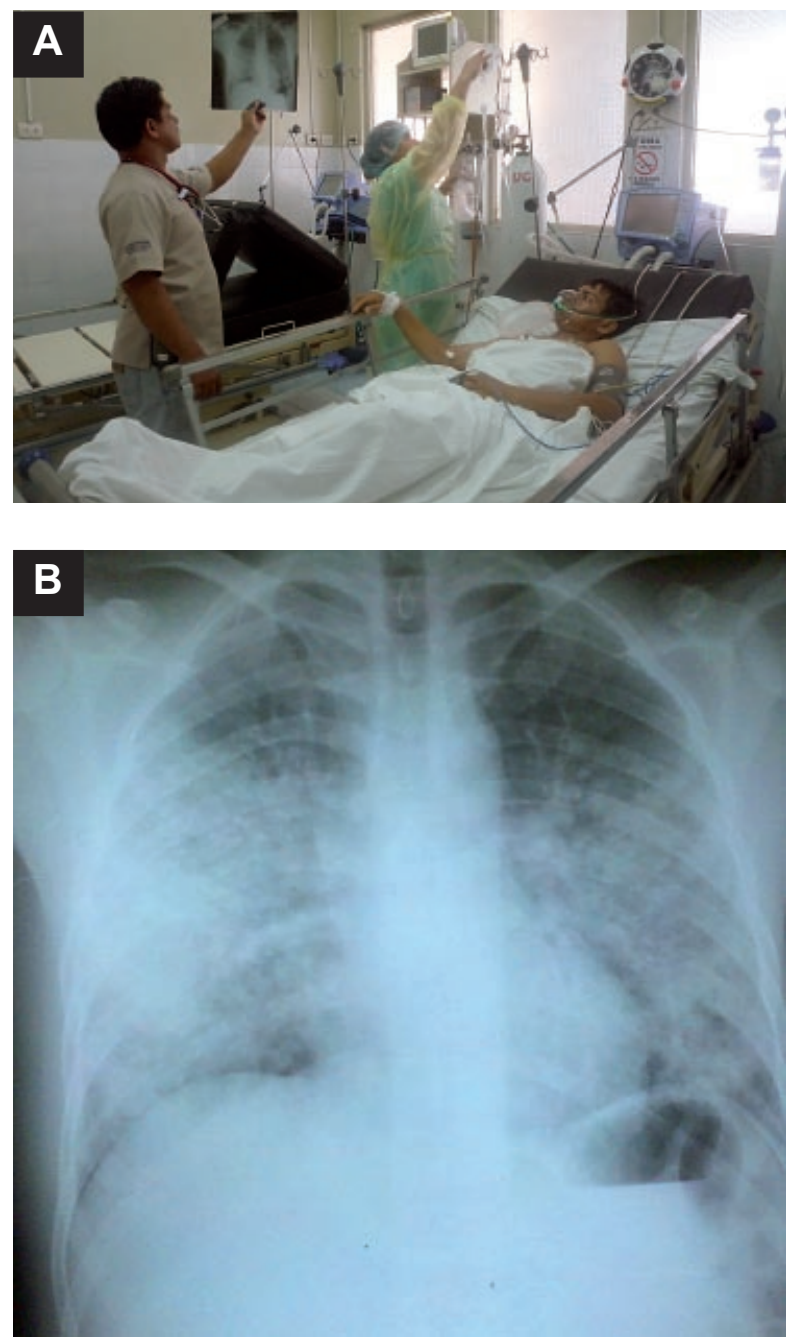

Figura 6. Manejo hospitalario de leptospirosis en la región Amazónica de Perú.

A) Caso de hemorragia pulmonar severa por Leptospira, manejado en la unidad de cuidados intensivos del Hospital Apoyo Iquitos; B) Radiografía de tórax del caso con infiltrado alveolar bilateral.
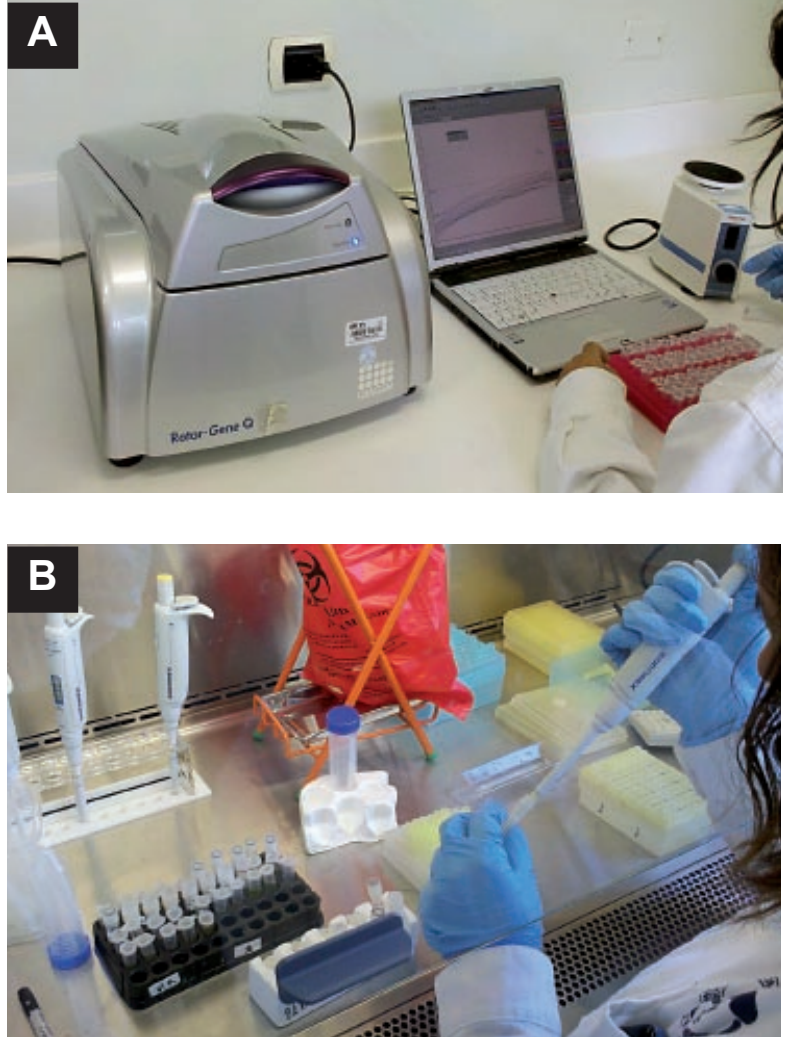

Figura 7. Fortalecimiento del diagnóstico de leptospirosis con técnicas serológicas y moleculares en el CIETROP "Hugo Pesce - Maxime Kuczynski" de la ciudad de lquitos.

A) Equipo de PCR en tiempo real para Leptospira sp. B) Procesamiento de muestras de suero para ELISA IgM de Leptospira $s p$

control de calidad de los diagnósticos en las regiones y el secuenciamiento genético de los aislamientos obtenidos.

\section{REFERENCIAS BIBLIOGRÁFICAS}

1. Levett PN, Haake DA. Leptospira Species (Leptospirosis). In: Mandell GL, Bennett JE, Dolin R (ed). Mandell, Douglas, and Bennett's Principles and Practice of Infectious Diseases, 7th ed. Orlando, FL: Saunders Elsevier; 2009.

2. Lau CL, Smytheb LD, Craigb SB, Weinsteina P. Climate change, flooding, urbanisation and leptospirosis: fuelling the fire?. Trans R Soc Trop Med Hyg. 2010;104(10):631-8.

3. Johnson MA, Smith H, Joeph P, Gilman RH, Bautista CT, Campos KJ, et al. Environmental exposure and leptospirosis, Peru. Emerg Infect Dis. 2004;10(6):1016-22.

4. Levett PN. Leptospirosis. Clin Microbiol Rev. 2001;14(2):296-326.

Correspondencia: Luis Fernando Donaires Toscano Dirección: Capac Yupanqui 1400, Lima 11, Perú.

Teléfono: (511) 6176200 Anexo: 2143

Correo electrónico: Idonaires@ins.gob.pe 